\title{
Research on Waste Capacity of Mountain-type Scenic Spots Based on Tourism Environmental Carrying Capacity Taking Huangshan as an example
}

\author{
Ying $\mathrm{Li}^{1}$, Jin Qian ${ }^{2, *}$, and Ting $\mathrm{Liu}^{1}$ \\ ${ }^{1}$ School of Tourism, Huangshan University, Anhui, China \\ ${ }^{2}$ Huangshan Tourism Development Co., LTD., Anhui, China
}

\begin{abstract}
The amount of solid waste generated by tourists and the scale of waste sorting points can be used to introduce the capacity of solid waste in the scenic spot. Based on tourism environmental capacity theory, this study based on previous research results, the solid waste carrying capacity of Huangshan Scenic area is calculated. The results show that the carrying capacity of the tourism environment in Huangshan Scenic Area is approaching saturation. According to the result, by providing a basic analysis for the treatment of domestic waste in Huangshan Scenic Area, this study confirms that the sustainable tourism development strategy is needed to everlasting natural resources.
\end{abstract}

\section{Introduction}

As an attempt to preserve nature, sustainability activities in the tourism sector are needed, which is called sustainability tourism. Sustainability tourism will balance the positive and negative impacts of tourism activities [1]. Reasonable carrying capacity greatly contributes to sustainable development. "Lucid waters and lush mountains are invaluable assets". The mountain-type scenic area can meet various tourism needs, such as sightseeing, leisure, fitness, and so on, because of its beautiful natural landscape and long history and traditional culture.. Compared with other districts, the mountain-type scenic area's geological characteristics and landforms are significantly different from other types of landscapes. But the special natural geographical environment has brought great difficulties to the local garbage collection, transportation, and disposal.

The main source of solid waste in the Huangshan Scenic Area is domestic garbage generated by tourists during the tourism process. It is mainly distributed along the tourist routes and attractions, as well as hotels and shops. Hotels, shops, etc. implement the principle of "who produces and who is responsible", and the output unit will transport them to the designated garbage room or garbage sorting and processing point by themselves. The number of employees engaged is a dynamic amount, which can be increased or decreased according to the number of tourists. Here, the garbage removal capacity will not be a limiting factor for the solid waste carrying capacity in the scenic spot. In the Huangshan Scenic Area, with the continuous influx of tourists, the natural ecology is also under great pressure. The location for this research is Huangshan Scenic Spot in Anhui Province, China (Fig.1). This paper takes a deep exploration of the solid waste carrying capacity of Huangshan Scenic Area, by providing a tourism environmental carrying capacity analysis system, scientifically and rationally design the garbage collection and transportation system in the scenic area.

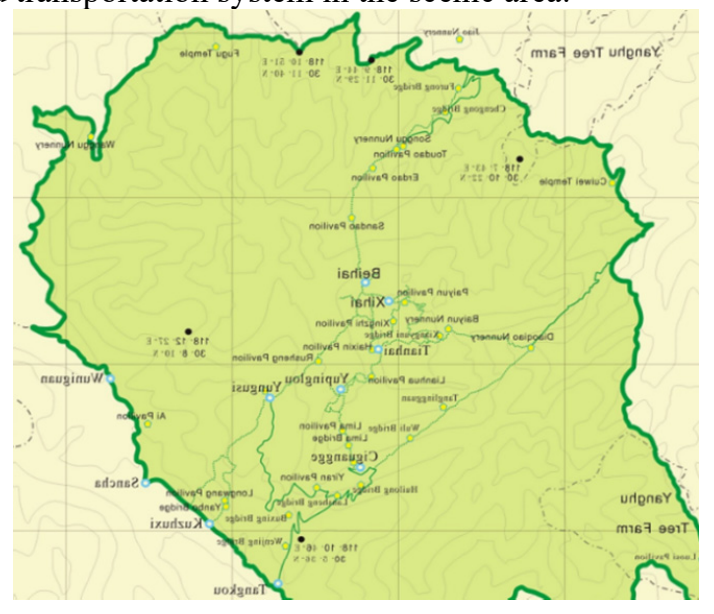

Fig 1. Huangshan Scenic Spot in Anhui Province

\section{Literature review and methodology}

The tourism carrying capacity assessment is based on the method proposed by Cifuentes in 1992 where the tourism carrying capacity is based on the area of activity as well as the period of tourism activities in each destination [2]. Tourism environmental carrying capacity includes four components: environmental ecological carrying capacity, resource space carrying capacity, economic carrying capacity, and psychological carrying capacity [3]. Environmental ecological carrying capacity depends on the four component values: water environment carrying 
capacity, atmospheric environment carrying capacity, and vegetation (Self-cleaning) capacity, and solid waste capacity (solid waste).

In terms of research on the concept of tourism environmental carrying capacity, in 1963, Lapage first raised the issue of "tourism environmental capacity". Lime and Stangey began to make in-depth discussions on tourism carrying capacity, and then more and more people studied this topic [4]. Wight and Wall put forward a more scientific definition of the concept of tourism carrying capacity in their book "Environmental Impact of Tourism Activities" [5]. They mainly conducted in-depth research on natural conditions such as water resources, air quality, and vegetation coverage, and proposed more systematic solutions. Lawson discussed the issue of tourism carrying capacity in the book "Recreation Tourism Development: Tourism Resources Evaluation Standards" [6]. In 1979, the World Tourism Organization released the "Report on Tourism Planning and Regional Development of the Six World Tourism Organizations." The report formally put forward the concept of tourism carrying capacity, and as a result, the environmental carrying capacity of tourism has gradually become an important concept in eco-tourism and sustainable development research.

In recent years, more and more researchers developed the study on the environmental carrying capacity. Weng et al. discussed the operation mode of the tourist area's environmental carrying capacity early warning system and proposed supporting measures to improve the system [7]. Zheng and Teng (2014) researched the tourist carrying capacity of tourist attractions in terms of daily space capacity, daily facility capacity, and environmental capacity under certain standards and requirements [8]. Based on the theories of smart tourism and smart scenic spots, the tourism scenic area's carrying capacity is divided into three phases: the base period, development period, and mature period, according to the wisdom trend of research progress in the carrying capacity of tourist scenic spots. By summarizing the relationship between the three, the framework diagram, and the inclusiveness characteristics Put forward countermeasures on related issues and provide the theoretical basis for subsequent research [9]. As for the Waste Capacity study, Tang (2015) used an index system including green areas, water volume, wastewater, and solid waste utilities to evaluate the coupling coordination between tourism and the environment [10]. Mateu-Sbert et al. (2013) estimated the impact of the tourist population on municipal solid waste generation. They concluded each additional tourist generates $0.160 \mathrm{~kg}$ of solid waste per day [11].

This paper uses the per capita output method to calculate the solid waste carrying capacity of the scenic area.

The formula of per capita production method:

$$
\mathrm{q} \times \mathrm{m}=\mathrm{Q}
$$

Among them, q---the amount of domestic garbage produced per capita;

m---solid waste bearing capacity;

Q---The scale of garbage sorting and processing point.

According to the "Master Plan for Huangshan Scenic Spots", the amount of garbage generated by tourists taking accommodation in the scenic spot is $1.3 \mathrm{~kg} / \mathrm{d}$; tourists without accommodation are $0.3 \mathrm{~kg} / \mathrm{d}$; service personnel and permanent residents are $1.0 \mathrm{~kg} / \mathrm{d}$.

The existing garbage sorting and processing points in Huangshan Scenic Area are located in Laodaokou, Tianhai, Beihai, and Xihai, a total of 4 , all have brick kilntype incinerators, respectively responsible for the domestic waste treatment of Yuping Scenic Area, Tianhai Scenic Area, Beihai Scenic Area, and Xihai Scenic Area. Table 1 shows the specific information of the 4 processing points.

Table1. Statistics table of Garbage Sorting and Disposal Point.

\begin{tabular}{|l|l|l|l|l|}
\hline Project & $\begin{array}{l}\text { Old } \\
\text { Crossing }\end{array}$ & Tianhai & Xihai & Beihai \\
\hline Site & $\begin{array}{l}\text { Old } \\
\text { crossing }\end{array}$ & Tianhai & Xihai & Beihai \\
\hline Construction time & 1997 & 1995 & 1995 & 1995 \\
\hline Area $\left(\mathrm{m}^{2}\right)$ & 180 & 200 & 200 & 200 \\
\hline $\begin{array}{l}\text { Treatment } \\
\text { process }\end{array}$ & Incinerate & $\begin{array}{l}\text { Incinera } \\
\text { te }\end{array}$ & $\begin{array}{l}\text { Incinera } \\
\text { te }\end{array}$ & $\begin{array}{l}\text { Incinera } \\
\text { te }\end{array}$ \\
\hline $\begin{array}{l}\text { Processing scale } \\
\text { (t/d) }\end{array}$ & 1.5 & 1.5 & 1.5 & 1.5 \\
\hline
\end{tabular}

Source: Scenic Area Development Management Company of Huangshan Tourism Development Co., Ltd.

\section{Temporal and spatial characteristics of solid waste carrying capacity in Huangshan Scenic Area}

\subsection{General characteristics: The total capacity is acceptable, and the medium and long term is insufficient}

Huangshan scenic spot has six hotels: Beihai Hotel, Shilin Hotel, Xihai Hotel, Paiyunlou Hotel, Baiyun Hotel, and Yuping Hotel. In the calculation of the number of beds, the suite is calculated as $1 \mathrm{bed} / \mathrm{room}$ and the standard room as 2 beds/room. The scenic spot has 3,382 beds, including 28 suites, 2,312 standard rooms, and 1,042 single-bathroom rooms for 4-6 people.

With the stationary increase of people's demand for tourism, especially after the foundation of The Dahuangshan National Park, the ticket price of scenic have been greatly reduced, which is bound to strongly stimulate the tourists' motivation. In the foreseeable future, the number of tourists will further increase, and may even explode, the solid waste carrying capacity of the scenic spot is facing severe challenges.

\subsection{Temporal characteristics: uneven load during low and peak seasons}

Scenic tourism is divided into low and peak seasons, and the monthly distribution of tourists is uneven. The Spring Festival and the National Day are peak seasons (see Table.2). And the average daily number of tourists shows explosive growth, far exceeding the daily solid waste carrying capacity. 
Table2. Huangshan Scenic Area 2015-2019 Holiday Tourists Scale.

\begin{tabular}{|l|l|l|}
\hline Year & Spring Festival & National Day \\
\hline 2016 & 127325 & 183941 \\
\hline 2017 & 188578 & 171773 \\
\hline 2018 & 140647 & 189613 \\
\hline 2019 & 148178 & 170741 \\
\hline
\end{tabular}

Source: Huangshan Tourism Development Co., Ltd. Scenic Area Development Management Company

\subsection{Spatial characteristics: uneven bearing}

Take Tianhai District as an example, calculate the solid waste carrying capacity of the scenic spot. Tianhai View Area is located in the center of Huangshan Scenic Area. It has Guangmingding, Aoyufeng, and other landscapes. It is also a transportation hub in the scenic area, and it must be visited by tourists. It is estimated that the number of tourists in Tianhai District accounts for more than $80 \%$ of the total tourists in the mountain. Since Tianhaihai District is the midpoint of the main tourist routes, both tourists and non-accommodating tourists will use Tianhaihaidian as the dining place for Chinese food. The amount of garbage generated by tourists will be $0.15 \mathrm{~kg} / \mathrm{d}$. There are 1 existing hotels in Tianhaihaihai District (Baiyun Hotel) ), There are 627 beds, 240 staffing staff, and the amount of garbage generated by the service staff is $1.0 \mathrm{~kg} / \mathrm{d}$. Since there is only one hotel in the Baiyun Hotel in Tianhaihai District, the location advantage is obvious, and the tourist occupancy rate is high.

It can be seen that the annual tourist volume and the average daily tourist volume of the scenic area in the past three years have exceeded the solid waste carrying capacity of the Tianhai District, and the number of tourists during the summer, small vacation, and Golden Week has far exceeded. According to this algorithm, it can be obtained the number of tourists per year. In general, the number determined through tourism carrying capacity assessment is the maximum number of tourists that Tianhai District can accommodate. It means tourism development and projection in Huangshan including for the specific destination must consider the result of Huangshan tourism carrying capacity. The result of the area from 2016-2019 is shown in Table 3 below.

Table3. Tianhai District Tourism Carrying Capacity.

\begin{tabular}{|l|l|l|}
\hline Year & $\begin{array}{l}\text { Solid Waste Carrying } \\
\text { Capacity/day }\end{array}$ & $\begin{array}{l}\text { Solid Waste Carrying } \\
\text { Capacity/year }\end{array}$ \\
\hline 2016 & 5611 & 2048015 \\
\hline 2017 & 5561 & 2029765 \\
\hline 2018 & 5543 & 2023195 \\
\hline 2019 & 5444 & 1987060 \\
\hline
\end{tabular}

\section{Analysis of influencing factors of solid waste carrying capacity in Huangshan Scenic Area}

\subsection{The influence of tourism space-time characteristics of Huangshan Scenic Area}

\subsubsection{Seasonal tourism}

In general, the seasonal variation of the amount of waste in the Huangshan Scenic Area is "four peaks and four valleys." There are four troughs in waste output, from November to January, March, May to June, and September.

The seasonal variation of the tourist volume time series of Huangshan Scenic Area also showed a "four peaks and four valleys" distribution, which coincided with the seasonal variation of garbage volume. In February, April, July-August, and October each year, there are four small peaks in tourist volume, which is the peak season of the scenic spot; the waste output in four years has four troughs, which are November-January, March, May-June, and September, of which November-January are the offseason, the lowest valley of the year, and March, MayJune, and September are the flat season. At the same time, from 2014 to 2016, with the increase in the number of tourists, the amount of garbage in the scenic area also increased year by year.

Climatic factors: The most suitable months for travel in the scenic area are from April to October. The scenic peak season is February, April, July-August, and October. Most of the peak season coincides with the most suitable travel month, indicating that the main factor affecting the seasonal changes in passenger flow in the scenic area is the natural seasonal factor. Compared with the big cities, the climate in the scenic spots is cooler in July and August every year, so tourists coming to Huangshan are mainly motivated by summer vacation.

Public holiday system factors: In terms of system suitability, because of the existence of public holidays, April, May, October, January-February winter holidays (New Year's Day, Spring Festival) and July-August summer holidays are suitable to travel months. The summer months of February, April, July-August, and October are consistent with the peak season of the scenic spot, indicating that the public holiday system factor is relatively important in the seasonal changes of Huangshan passenger flow. Although January includes New Year's Day and the student's winter vacation, the area is still offseason due to the colder weather and the New Year's Day long holiday highway is not free. Although there is a "May 1 " long holiday in May, the high-speed is not free.

Marketing policy factors: Major preferential activities launched at specific times in the scenic area will also affect the seasonality of tourism. A more typical situation is the "September 1-7th Hangzhou citizens free tour of Huangshan" launched in September 2016 for the G20 Summit ". Due to the explosive growth of tourists in Hangzhou, the usual season was the peak season in September 2016, which became the peak season. 408,132 
tourists were entering the mountain throughout the month, and the amount of garbage in the month also reached 268.42 tons, a record high.

\subsubsection{Unbalanced development of tourism space}

The uneven development of tourism space makes the spatial distribution of tourists show uneven characteristics, which affects the output distribution of solid waste. Specifically: Beihai District: mature development, gentle terrain, many hotels, large tourist capacity, a large number of tourist attractions, high quality, a high degree of aggregation, and a great attraction for tourists. Xihai Sea District: The tourism resources are highly concentrated, but the location is biased, the external traffic is poorly connected, the terrain is steep, and the walking trails are steep and long, suitable for young people to explore. Tianhai District: Located in the center of Huangshan Scenic Area, it is the midpoint of the main tourist routes and the transportation hub of the scenic spot. It has a high degree of development and is a major distribution center for tourists. The location advantage is obvious. Yuping Scenic Area: There are well-known landscapes such as the welcome pine, but it is limited by the terrain, the space is insufficient, the hotel is small and small, and the tourist capacity is small.

Due to the differences in tourism resources and development, the spatial distribution of tourists is uneven. The Tianhai District and the Beihai District have a large number of tourists, a large amount of garbage output, and a large pressure on the solid waste load; the Yuping Scenic Area has the least pressure on the solid waste load.

\subsection{Impact of garbage disposal methods in Huangshan Scenic Area}

The incinerator currently used in the Huangshan Scenic Spot waste sorting and processing site is an earthen brick kiln, and the waste treatment process is simple. Due to the insufficient waste disposal capacity and low solid waste carrying capacity in the scenic spot, the waste sorting and processing point is overloaded, resulting in the waste incineration time not meeting the required requirements, the waste incineration is insufficient, and a large amount of acid gas and incomplete combustion are generated during the incineration process. Dioxin and other highly toxic carcinogenic organic ingredients. The perishable organic waste in the scenic area, including kitchen waste, has a high moisture content after being mixed and collected, and the temperature does not meet the requirements during simple incineration treatment, resulting in a high content of harmful components in the incineration exhaust gas, and also causing a heavy odor in the incineration site and easy to breed mosquitoes. The phenomenon of flies has seriously polluted the surrounding environment and has also caused physical and mental health hazards to workers in the waste incineration operation. Due to the constraints of planning and fire prevention, bag dust removal technology cannot be used for soot treatment, and simple water curtain dust reduction technology is still used. The incineration tail gas cannot be discharged in compliance with the standards, and the content of toxic substances (dioxins) in the circulating water of soot is high and difficult to handle deal with.

It can be seen that flue gas and wastewater have become the main sources of secondary pollution during the garbage disposal process in the scenic spot, which seriously polluted the atmosphere, soil, and groundwater. Besides, the scenic area stipulates that during the "Spring Festival", "Golden Week", and the reception period of the task, the burning of garbage is prohibited, resulting in the accumulation of garbage after the Golden Week and the reception task, which in turn brings more serious pollution problems.

\section{Conclusion}

The assessment of tourism carrying capacity can be a powerful basis for tourism management and control in Huangshan Scenic Spot. It can be seen from the data results that the tourism environment carrying capacity of Tianhai Scenic Spot has reached saturation. This is only one of the main scenic spots in Huangshan Scenic Area. This means that the current treatment of domestic waste in scenic spots will cause serious pollution and safety problems, and it can no longer meet the requirements of ecological protection, and urgently needs to transform and upgrade. It is imperative to reform the current model and establish a new model of domestic garbage disposal that is coordinated with resource development and environmental protection.

The recommendation for tourism development in Huangshan Scenic Spot is the development of ecotourism as the main potentials where the number of tourists must be measurable primarily in the destination that has a low tourism carrying capacity. Huangshan tourism development must pay attention to the tourism carrying capacity. The development of the destinations should not focus on the number of tourists but focus on the other indicators such as preservation function or economic benefits.

All the results of tourism carrying capacity can be factors for tourism development policies. In general, it can create balanced regional development from not only tourism benefits but also environmental outcomes. The stakeholders also must consider tourism carrying capacity to create and to realize sustainable ecotourism in Huangshan.

\section{Acknowledgement}

Key Project of Humanities and Social Science Research of Anhui Provincial Education Department (SK2019A0429); Major Project of Humanities and Social Science Research of Anhui Provincial Education Department (SK2020ZD38); Scientific Research Project of Anhui Province Tourism Talent Training Demonstration Base (YYRCYB1704) 


\section{References:}

1. Z. Jurigova, Z.Lencsesova. J Competitiveness, 7, 35 (2015)

2. M. Cifuentes, F. Alpizar, F. Barroso. CATIE Serie técnica, Turrialba. (1992)

3. Y.Zhao, L.Jiao. Ecol Process, 8 (2019) (online)

4. D. W. Lime, G. H. Stankey. The Forest Recreation Symposium.174 (1971)

5. G.Wall, C.Wright. Ontario: University of Waterloo, 53 (1977)

6. Lawson F.M. Boyd-Bovy. United Kingdom: Architectural Press, 66 (1977)

7. G.Weng, L.Zhao, X.Yang. J China Univ Geosci, 4 (2005)

8. Y.Zheng, Y.Teng. Urban Tourism Planning, 2: 174 (2014)

9. Y. Yuan, N. Chen, C. Cheng. Tourism Forum, 3(2016)

10. Z.Tang, Tour. Manag. 46, 11-19 (2015)

11. J. Mateu-Sbert, I. Ricci-Cabello, E. Villalonga-Olives,

E. Cabeza-Irigoyen. Waste Manag. 33, 2589 (2013) 